JURNAL RISET REKAYASA ELEKTRO

Vol.2, No.2, Desember 2020, Hal. 39 48

P-ISSN: 2685 - $4341 \quad$ E-ISSN: 2685 - 5313

\title{
Simulasi Relay Jarak Sebagai Proteksi Saluran Transmisi Dengan Penentuan Lokasi Titik Gangguan Menggunakan Arduino Dengan Penampil HMI (Human Machine Interface)
}

Wahyu Widodo ${ }^{1}$, Arif Johar Taufiq ${ }^{2}$

Program Studi S1 Teknik Elektro, Universitas Muhammadiyah Purwokerto Fakultas Teknik dan Sains, Universitas Muhammadiyah Purwokerto

\section{Informasi Makalah}

Dikirim, 19 Agustus 2020

Direvisi, 17 Desember 2020

Diterima, 29 Desember 2020

\section{Kata Kunci:}

Sensor arus ACS712

Sensor Tegangan ZMPT101B HMI

Impedansi One-end

\section{INTISARI}

Stabilitas sistem tenaga yaitu keadaan sistem merespon gangguan saat operasi normal dengan mengembalikan sistem ke kondisi normal kembali. Gangguan pada sistem tenaga dapat menimbulkan osilasi terhadap variabel-variabel sistem tenaga seperti tegangan, frekuensi, dan daya. Konsumen listrik menghendaki sistem yang andal yaitu dimana variabel tersebut bernilai tetap pada suatu titik operasi tertentu. Pada penelitian ini dilakukan Simulasi Relay Jarak Sebagai Proteksi Saluran Transmisi Dengan Penentuan Lokasi Titik Gangguan Menggunakan Arduino Dengan Penampil HMI (Human Machine Interface) menggunakan data gangguan transmisi pada GI Kalibakal UPT Purwokerto. Penentuan lokasi gangguan menggunakan impedansi one - end yaitu perhitungan reaktansi sederhana dengan melihat arus dan tegangan sebagai parameternya. Sistem bekerja ketika terjadi kenaikan arus pada saluran yang signifikan yang diolah oleh Arduino sehingga didapat data jarak gangguan yang kemudian data dikirim ke Microsoft Access untuk disimpan dan ditampilkan pada HMI, tampilan HMI dibuat melalui program Vijeo Citect dari Schneider. Sedangkan komunikasi antara Arduino Mega 2560 Pro dan HMI menggunakan komunikasi kabel RJ45. Hasil dari penelitian didapat pembacaan deteksi gangguan pada modul memiliki error sebesar $10 \%-15 \%$ jika dibandingkan dengan data gangguan pada GI Kalibakal.

\section{Keyword:}

Current Sensor ACS712

Voltage Sensor ZMPT101B

HMI

Impedance one-end

\begin{abstract}
Power system stability is the state of the system responds to interference when normal operation by restoring the system to a normal back state. Interference in the power system can cause oscillation of power system variables such as voltage, frequency, and power. Electricity consumers require a reliable system that is where the variables are worth staying at a particular operating point. In this research conducted simulation Relay distance as transmission line protection with the determination of the location of the disturbance point using Arduino with the viewer hmi (Human Machine Interface) using transmission interference data in the Kalibakal UPT of Purwokerto. Determination of the location of interference using one-end impedance is simple reactance calculation by looking at the current and voltage as the parameters. The system works when there is a current increase in the significant channel that is processed by the Arduino so that a data distance interruption is obtained which is then sent to Microsoft Access to BE stored and displayed on HMI, the HMI display is created through the vijeo citect program of Schneider. While the communication between Arduino Mega 2560 Pro and HMI uses RJ45 cable communication. The results of the study obtained impaired detection readings in the module had an error of 10\%-15\% when compared with the disruption data on the Kalibakal GI.
\end{abstract}




\author{
Korespondensi Penulis: \\ Wahyu Widodo \\ Program Studi Teknik Elektro \\ Fakultas Teknik dan Sains Universitas Muhammadiyah Purwokerto \\ JL. KH. Ahmad Dahlan Purwokerto, 53182 \\ Email: wahyuw793@gmail.com
}

\title{
1. PENDAHULUAN
}

Sistem transmisi merupakan bagian penyaluran tenaga listrik dari pembangkitan generator sampai pada pendistribusian yang menggunakan arus bolak balik (AC) sistem tiga phasa.Error! Reference source not found.

Stabilitas sistem tenaga yaitu keadaan sistem merespon gangguan saat operasi normal dengan mengembalikan ke suatu kondisi operasi normal kembali. Gangguan pada sistem dapat menimbulkan osilasi terhadap variabel-variabel sistem, seperti tegangan, frekuensi, dan daya. Kebutuhan tenaga listrik menghendaki sistem yang andal yaitu dimana variabel tersebut di atas bernilai tetap pada suatu titik operasi tertentu.[2]

Gangguan pada sistem tenaga listrik merupakan segala macam kejadian yang menyebabkan kondisi pada sistem tenaga listrik menjadi abnormal. Jika ditinjau dari sifat dan penyebabnya jenis gangguan pada sistem tenaga listrik dapat dikelompokkan menjadi empat bagian, yaitu: tegangan lebih (over voltage), hubungan singkat (short circuit), daya balik (Reserve Power), dan beban lebih (over load), salah satu yang menyebabkan kondisi gangguan pada sistem tenaga listrik yang banyak terjadi ialah gangguan hubung singkat, dimana gangguan hubung singkat ini dapat dibagi menjadi dua bagian, yaitu: gangguan simetris dan gangguan tidak simetris (asimetris).[2]Gangguan pada sistem tenaga listrik dapat kita ketahui titik gangguannya menggunakan metode diantara lain:

1. Pencocokan data hubung singkat dan DFR.

2. Metode pengecekan gelombang transmisi.

3. Metode berdasarkan impedansi.

Peneliti memiliki gagasan untuk membuat simulasi relay jarak Sebagai Proteksi Saluran Transmisi Dengan Penentuan Lokasi Titik Gangguan Menggunakan Arduino Dengan Penampil HMI (Human Machine Interface) dengan menggunakan sensor arus ACS712 dan sensor tegangan ZMPT101B kemudian dengan memanfaatkan komunikasi kabel RJ45 sebagai pengiriman data simulasi gangguan menggunakan konfigurasi IP, data simulasi gangguan kemudian ditampilkan oleh HMI (Human Machine Interface). Sehingga dengan digunakannya komunikasi kabel RJ45 dirasa lebih efisien, karena dhasil pengukuran data simulasi gangguan dapat dengan mudah dimonitoring jarak jauh melalui perangkat komputer.

\section{METODE PENELITIAN}

\subsection{Diagram Flowchart Sistem}

Simulasi relay jarak yang dibuat bekerja berdasarkan sensor yang digunakan untuk melakukan pengukuran, data hasil pengukuran sensor kemudian disimpan pada database MS. Access menggunakan Open database Connectivity (ODBC) yang berfungsi sebagai jembatan antara hasil pengukuran sensor dengan database MS. Access, pada diagram flowchart berikut berfungsi untuk membuat alur jalannya sistem yang dibuat, perancangan ini juga digunakan sebagai urutan dalam jalannya sistem simulasi relay jarak sebagai proteksi saluran transmisi. Flowchart sistem seperti Gambar 1 berikut. 


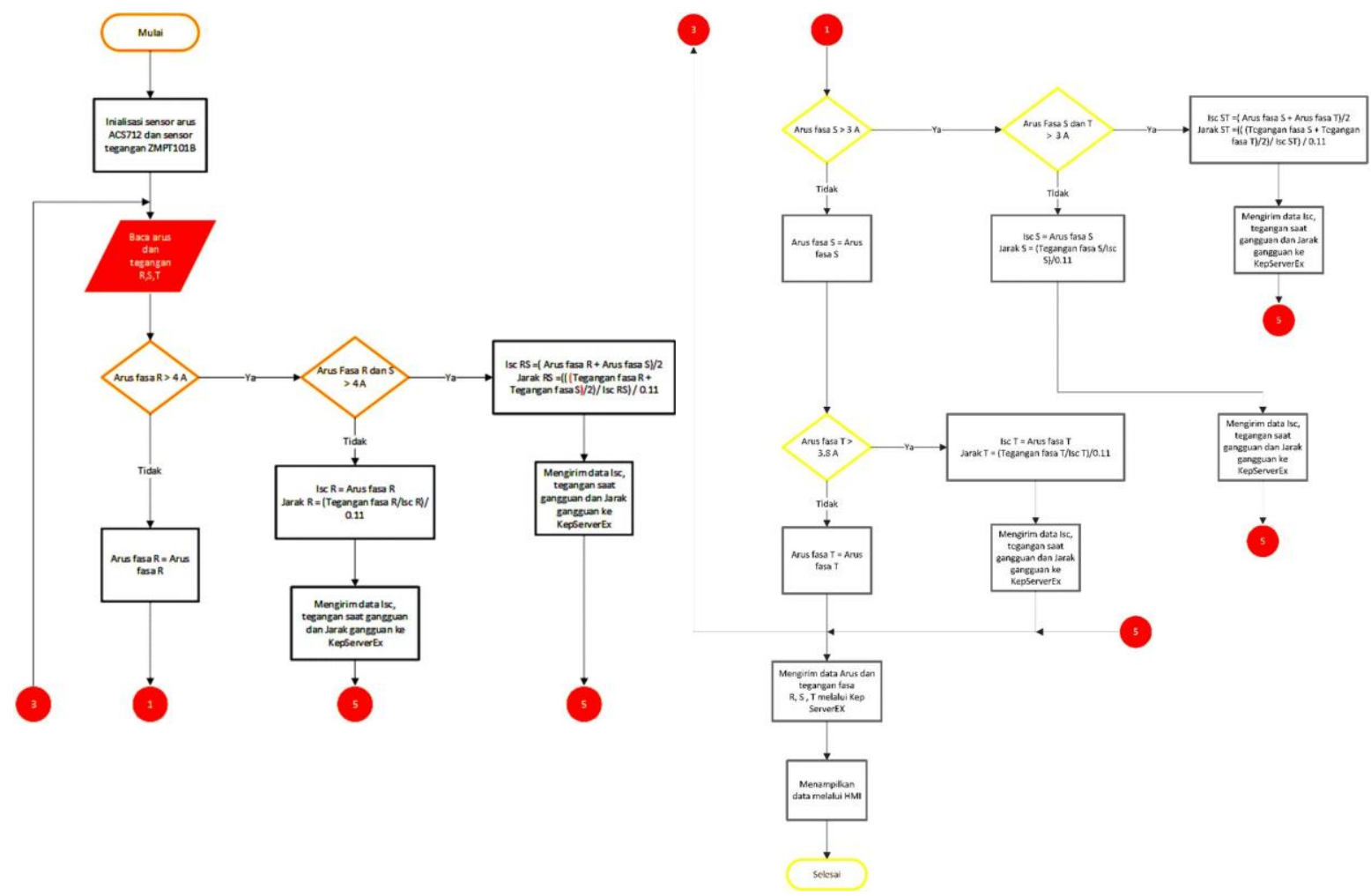

Gambar 1. Flowchart Sistem Simulasi Relay Jarak.

\subsection{Perancangan Perangkat}

Modul simulasi gangguan ini menggunakan board Arduino untuk pengolahan data yang terhubung dengan sensor arus dan tegangan. Simulasi gangguan pada modul menggunakan saklar untuk mewakili terjadi gangguan hubung singkat. Hasil pengukuran data akan ditampilkan pada HMI, perancangan perangkat keras ditunjukan pada Gambar 2.

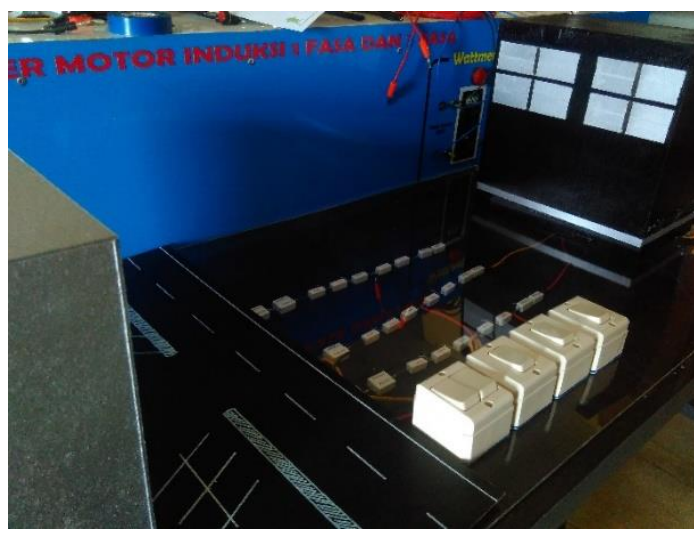

Gambar 2. Modul Simulasi Gangguan.

\subsection{Pengujian Simulasi Relay Jarak dan Perhitungan Jarak Gangguan}

Pengujian yang dilakukan pada modul gangguan menggunakan 5 jenis gangguan hubung singkat yang mengikuti skema gangguan yang terjadi pada GI Kalibakal. Pengambilan data dilakukan dengan cara menghubungkan saluran pada modul simulasi gangguan sebanyak 5 kali setiap 1 jenis gangguan yang disimulasikan, hasil simulasi gangguan yang dilakukan kemudian dibandingkan dengan alat yang digunakan pada GI Kalibakal sehingga dapat diketahui tingkat akurasi dan eror yang terdapat pada sensor yang digunakan. 
Perhitungan titik gangguan menggunakan metode impedansi one - end dengan menggunakan rumus reaktansi sederhana, persamaan yang digunakan sebagai berikut.

$$
m=\frac{\left(\frac{V G}{I G}\right)}{Z_{L 1}}
$$

Keterangan:

$\begin{array}{ll}m & =\text { Jarak gangguan } \\ \mathrm{VG} & =\text { Tegangan ketika gangguan } \\ \mathrm{IG} & =\text { Arus ketika gangguan } \\ Z_{L 1} & =\text { Impedansi/ Resistansi pada saluran transmisi GI Kalibakal - Bumiayu }\end{array}$

\section{HASIL DAN PEMBAHASAN}

Setelah dilakukan pembuatan alat dan pengujian terhadap seluruh rangkaian maka diperoleh hasil berupa suatu sistem simulasi relay jarak sebagai proteksi saluran transmisi seperti ditunjukan pada Gambar 3 sementara pada Gambar 4 merupakan tampilan HMI pada simulasi relay jarak

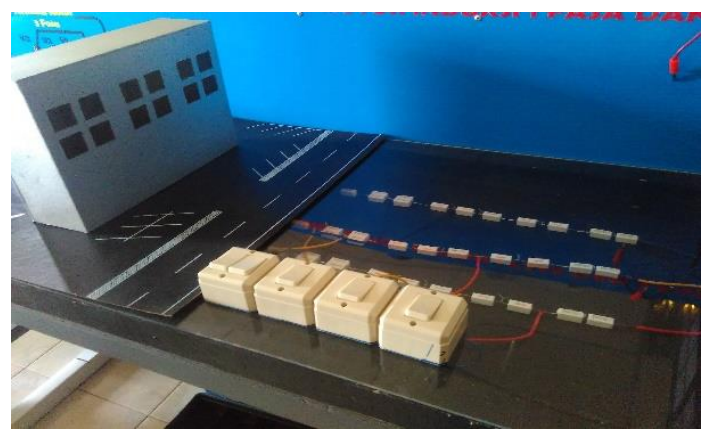

Gambar 3. Perangkat Keras Sistem Simulasi Relay Jarak.

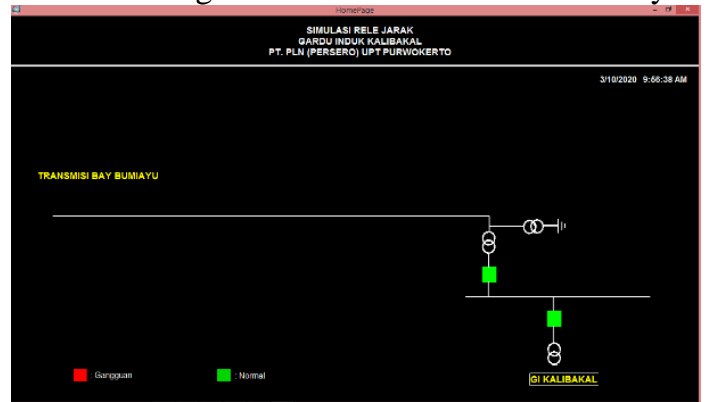

Gambar 4. Tampilan HMI pada Simulasi Relay Jarak.

\subsection{Pengujian Sensor Arus dan Tegangan}

Pengujian sensor dilakukan untuk mengetahui apakah hasil pembacaan sudah sesuai dengan datasheet atau belum. Pengujian dilakukan dengan memberikan tegangan dan beban yang variatif langsung ke sensor arus ACS712 dan sensor tegangan ZMPT101B. Pengujian sensor arus ini dilakukan kepada 3 sensor arus yang nantinya akan mewakili fasa $\mathrm{R}, \mathrm{S}$, T dengan menggunakan variasi beban yang berubah ubah nilainya. Pengujian ini dilakukan dengan menguji CT sensor satu per satu dimana CT 1 mewakili fasa R, CT 2 mewakili fasa S, dan CT 3 mewakili fasa T. Pengujian ini dilakukan agar kita bisa mendapatkan nilai error pada sensor arus ACS712 dengan alat ukur yang telah terstandar yaitu Clamp ampere Krisbow KW06-287 Hasil pengujian sensor arus ditampilkan pada Tabel 1 . 
Tabel 1. Pengujian Sensor Arus ACS712.

\begin{tabular}{cccccccccc}
\hline $\begin{array}{c}\text { Beban } \\
\text { (Watt) }\end{array}$ & $\begin{array}{c}\text { Clamp } \\
(\mathrm{A})\end{array}$ & $\begin{array}{c}\text { CT 1 } \\
\text { Serial } \\
\text { Monitor } \\
(\mathrm{A})\end{array}$ & $\begin{array}{c}\text { Error } \\
(\%)\end{array}$ & $\begin{array}{c}\text { Clamp } \\
(\mathrm{A})\end{array}$ & $\begin{array}{c}\text { CT 2 } \\
\text { Serial } \\
\text { Monitor } \\
(\mathrm{A})\end{array}$ & $\begin{array}{c}\text { Error } \\
(\%)\end{array}$ & $\begin{array}{c}\text { Clamp } \\
(\mathrm{A})\end{array}$ & $\begin{array}{c}\text { CT 3 } \\
\text { Monitor } \\
(\mathrm{A})\end{array}$ & $\begin{array}{c}\text { Error } \\
(\%)\end{array}$ \\
\hline 30 & 0,1 & 0,11 & 9 & 0,1 & 0,11 & 9 & 0,1 & 0,11 & 9 \\
45 & 0,2 & 0,21 & 4,7 & 0,2 & 0,2 & 0 & 0,2 & 0,2 & 0 \\
60 & 0,2 & 0,28 & 20 & 0,2 & 0,25 & 20 & 0,2 & 0,25 & 20 \\
90 & 0,3 & 0,4 & 25 & 0,3 & 0,46 & 25 & 0,3 & 0,38 & 24 \\
160 & 0,5 & 0,68 & 26 & 0,5 & 0,7 & 26 & 0,5 & 0,65 & 26 \\
235 & 0,7 & 1 & 30 & 0,7 & 1 & 30 & 0,7 & 0,98 & 30 \\
\hline
\end{tabular}

Pada pengujian sensor tegangan ini, kami melakukan kalibrasi Sensor ZMPT101B untuk mendapatkan tingkat akurasi pembacaan arus sebaik mungkin.Pengujian dilakukan kepada 3 sensor tegangan yang nantinya akan mewakili fasa R, S, T dengan menggunakan variasi tegangan yang berubah ubah nilainya dengan alat VARIAC. Pengujian ini dilakukan agar kita bisa mengetahui nilai error pada sensor tegangan ZMPT101B dengan alat ukur yang telah terstandar yaitu Multimeter Sanwa CD800a. Hasil pengujian sensor tegangan ditampilkan pada Tabel 2.

Tabel 2. Pengujian Sensor Tegangan ZMPT101B.

\begin{tabular}{rrrrrrrr}
\hline $\begin{array}{c}\text { Variac } \\
(\mathrm{V})\end{array}$ & $\begin{array}{c}\text { Multi } \\
\text { CD800a } \\
(\mathrm{V})\end{array}$ & $\begin{array}{c}\text { Sensor } \\
\text { Fasa R (V) }\end{array}$ & $\begin{array}{c}\text { Error } \\
(\%)\end{array}$ & $\begin{array}{l}\text { Sensor } \\
\text { Fasa S }\end{array}$ & $\begin{array}{c}\text { Error } \\
(\%)\end{array}$ & $\begin{array}{c}\text { Sensor } \\
\text { Fasa T }\end{array}$ & $\begin{array}{c}\text { Error } \\
(\%)\end{array}$ \\
\hline 0 & 0,52 & 0,60 & 14,72 & 0,60 & 14,72 & 0,60 & 14,72 \\
6 & 6,03 & 4,67 & 22,55 & 4,65 & 22,89 & 4,19 & 30,51 \\
12 & 12,14 & 10,74 & 11,53 & 11,28 & 7,08 & 11,27 & 7,17 \\
24 & 24,27 & 23,44 & 3,42 & 23,52 & 3,09 & 23,67 & 2,47 \\
48 & 48,10 & 46,49 & 3.35 & 47,50 & 1,25 & 47,00 & 2,29 \\
75 & 75,20 & 73,47 & 2,30 & 73,97 & 1,64 & 73,43 & 2.35 \\
100 & 100,00 & 100,28 & 0,28 & 100,87 & 0,87 & 100,33 & 0,33 \\
120 & 120,30 & 118,08 & 1,85 & 119,28 & 0,85 & 118,40 & 1,58 \\
150 & 150,20 & 149,5 & 0,47 & 151,07 & 0,58 & 149,50 & 0,47 \\
170 & 170,20 & 169,24 & 0,62 & 170,71 & 0,24 & 168,59 & 1,00 \\
200 & 200,20 & 198,64 & 0,78 & 201,43 & 0,61 & 198,19 & 1,00 \\
220 & 220,10 & 221,14 & 0,47 & 222,33 & 1,01 & 220,59 & 0,22 \\
\hline
\end{tabular}

\subsection{Pengujian Modul ENC28J60}

Pengujian modul ini dilakukan agar mengetahui apakah data yang dikirimkan melalui komunikasi RJ45 terkirim sesuai pengalamatan atau tidak. Hasil pengujian dapat dilihat pada Gambar 5.

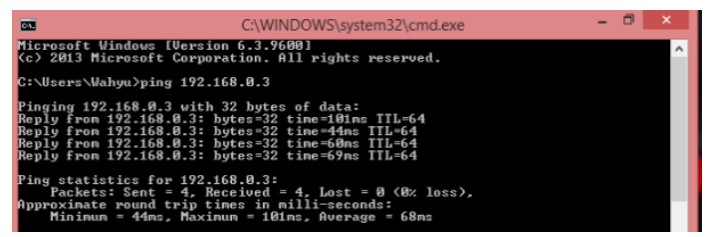

Gambar 5. Pengujian Modul ENC28J60 Melalui Laptop.

\subsection{Pengujian Modul Simulasi Gangguan Relay Jarak}

Pengujian modul simulasi gangguan ini dilakukan untuk mencari nilai arus yang mengalir dan juga tegangan yang ada pada modul gangguan dan juga beban yang dipakai. Pengujian ini diperlukan agar kita dapat menganalisa kerja modul gangguan agar sesuai dengan yang kita rancang dan sudah siap dilakukan uji keseluruhan sistem. Skema pengujian modul simulasi gangguan dapat dilihat pada Gambar 6 dan hasil pengujian terdapat pada Tabel 3. 


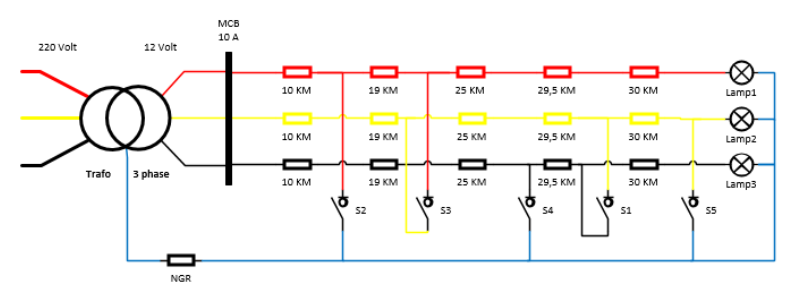

Gambar 6. Skema Rangkaian Simulasi Relay Jarak

Tabel 3. Hasil Simulasi Hubung Singkat Relay Jarak

\begin{tabular}{cccccccccc}
\hline $\begin{array}{c}\text { Jenis } \\
\text { Gangguan }\end{array}$ & $\mathrm{R}$ & $\mathrm{Isc}(\mathrm{A})$ & \multicolumn{3}{c}{ Vsc $(\mathrm{V})$} & \multicolumn{2}{c}{ Jarak } & Waktu & Keterangan \\
& $\mathrm{S}$ & $\mathrm{T}$ & $\mathrm{R}$ & $\mathrm{S}$ & $\mathrm{T}$ & Gangguan & Gangguan & \\
\hline 1 Fasa & 7,02 & - & - & 9,34 & - & - & $10,4 \mathrm{KM}$ & $11.30 \mathrm{WIB}$ & Fasa R-N \\
1 Fasa & - & 3,08 & - & - & 11,12 & - & $38 \mathrm{KM}$ & $11.31 \mathrm{WIB}$ & Fasa S-N \\
1 Fasa & - & - & 3,68 & - & - & 10,41 & $23,4 \mathrm{KM}$ & $11.31 \mathrm{WIB}$ & Fasa T-N \\
2 Fasa & 4,58 & 4,61 & - & 10,61 & 10,86 & - & $21,8 \mathrm{KM}$ & $11.32 \mathrm{WIB}$ & Fasa R-S \\
2 Fasa & - & 3,11 & 3,08 & - & 11,27 & 11,18 & $32,7 \mathrm{KM}$ & $11.33 \mathrm{WIB}$ & Fasa S-T \\
\hline
\end{tabular}

\subsection{Pengujian HMI Ketika Simulasi Gangguan}

Hasil pembacaan sensor dan pengolahan data simulasi gangguan kemudian akan ditampilkan pada HMI yang aplikasinya dibuat dengan VijeoCitect. Hasil pembacaan sensor dapat dilihat pada Gambar 7 dan hasil pengolahan data simulasi gangguan pada Gambar 8, Gambar 9, dan Gambar 10.

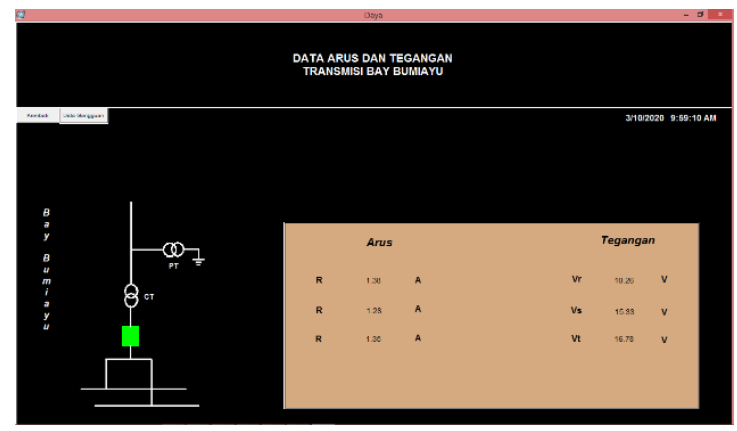

Gambar 7. Tampilan Pembacaan Sensor Arus dan Tegangan pada HMI.

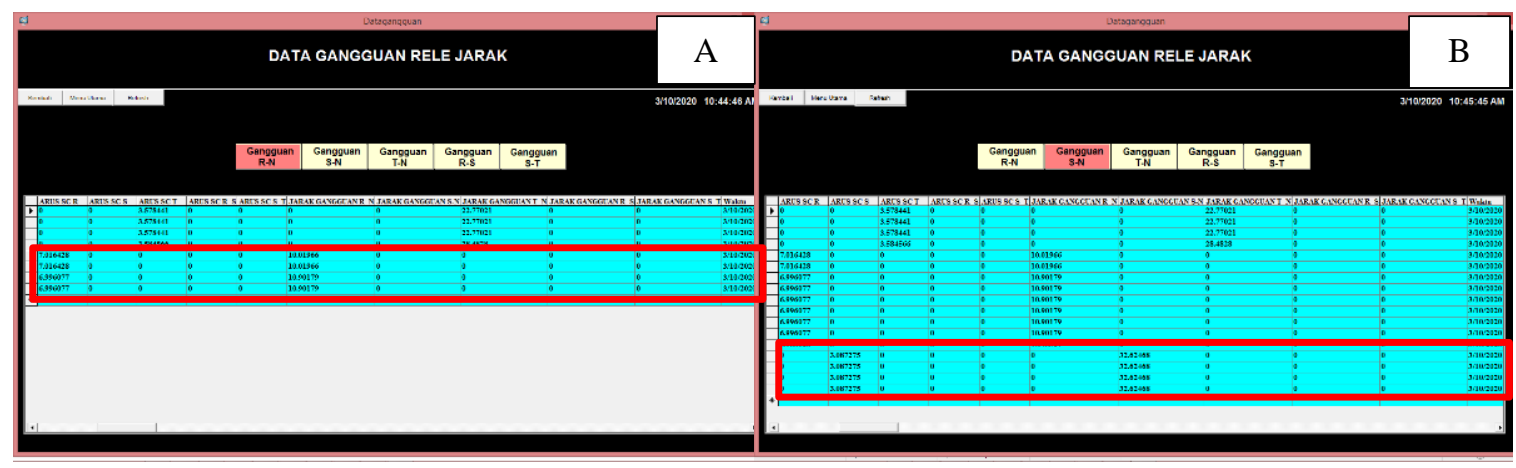

Gambar 8. Hasil Simulasi Deteksi Titik Gangguan pada HMI Fasa R (A) dan Fasa S (B). 


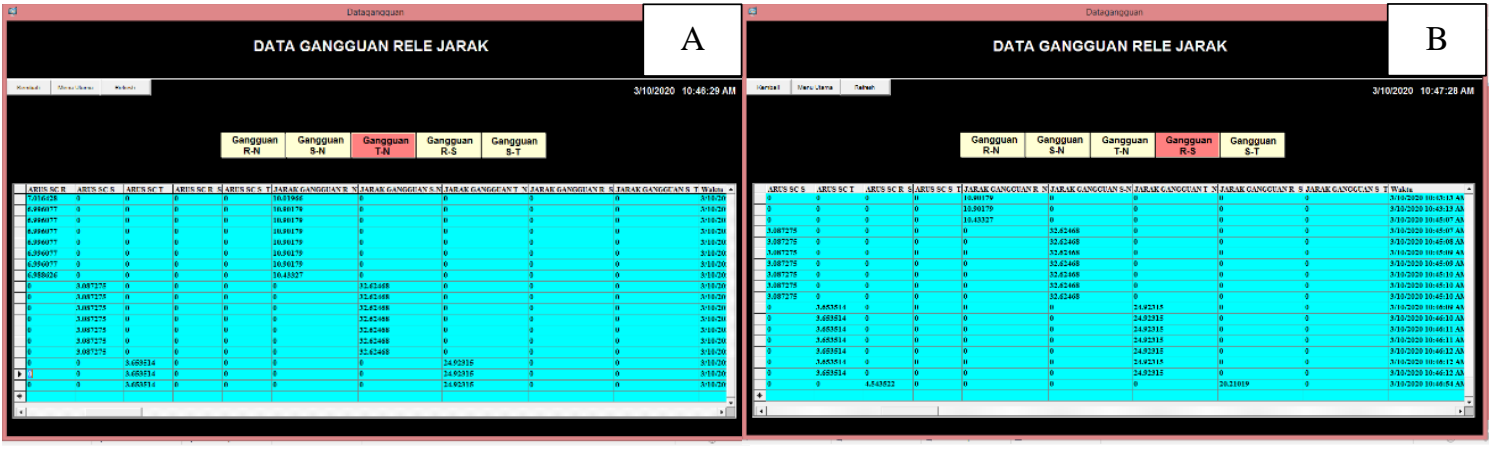

Gambar 9. Hasil Simulasi Deteksi Titik Gangguan pada HMI Fasa T (A) dan Fasa R-S (B).

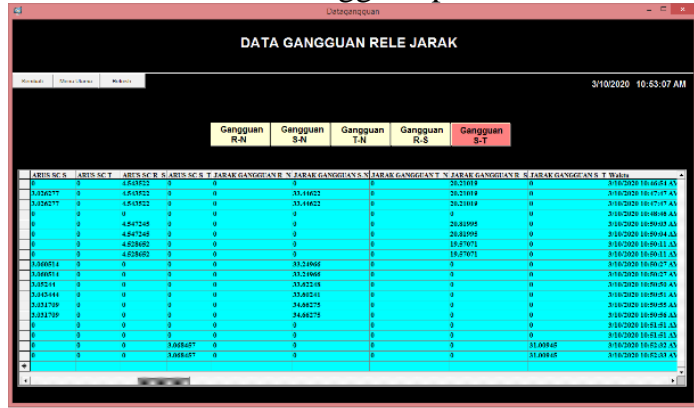

Gambar 10. Hasil Simulasi Deteksi Titik Gangguan pada HMI Fasa S-T.

\subsection{Pengujian Database MS. Access}

Pengujian ini bertujuan untuk mengetahui apakah data hasil monitoring dapat tersimpan dengan baik pada database MS. Accesss yang dibuat, sehingga apabila akan dilakukan audit data dapat dilakukan dengan mudah. Hasil data simulasi gangguan yang tersimpan oleh database dapat dilihat pada Gambar 11.

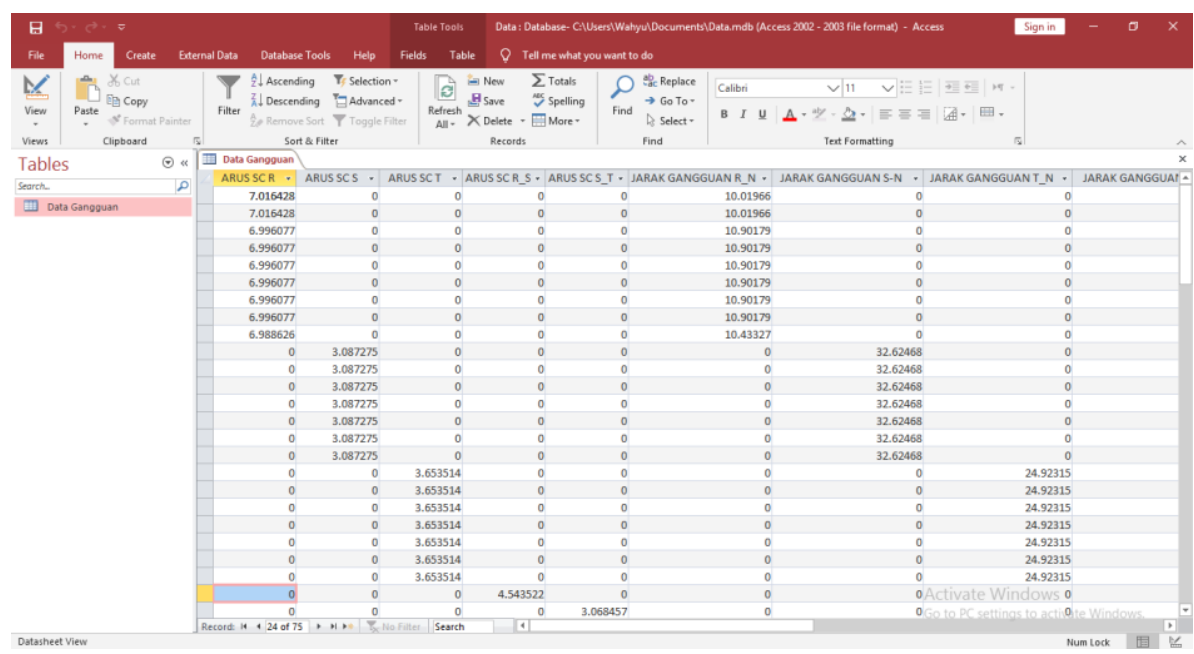

Gambar 11. Hasil Simulasi Relay Jarak yang Tersimpan pada database.

Hasil simulasi yang dilakukan dapat dilihat pada Tabel 3 dan data real gangguan pada relay jarak GI Kalibakal UPT Purwokerto pada Tabel 4. 
Tabel 4. Data Gangguan real pada Relay Jarak GI Kalibakal.

\begin{tabular}{ccccrc}
\hline No & $\begin{array}{c}\text { Jenis } \\
\text { Gangguan }\end{array}$ & $\begin{array}{c}\text { Relay } \\
\text { Bekerja }\end{array}$ & Zona & Jarak & Waktu Gangguan \\
\hline 1 & 2 fasa & Fasa RS-N & 1 & $19 \mathrm{KM}$ & $14.22 \mathrm{WIB}$ \\
2 & 3 fasa & Fasa RST-N & 1 & $29,5 \mathrm{KM}$ & $14.22 \mathrm{WIB}$ \\
3 & 2 fasa & Fasa RS-N & 1 & $19 \mathrm{KM}$ & $14.25 \mathrm{WIB}$ \\
4 & 3 fasa & Fasa RST-N & 1 & $29,5 \mathrm{KM}$ & $14.25 \mathrm{WIB}$ \\
\hline
\end{tabular}

Sumber: GI Kalibakal, UPT Purwokerto

Dari hasil pengujian simulasi yang menggunakan skema gangguan pada GI Kalibakal kemudian dibandingkan dengan data gangguan real pada relay jarak GI Kalibakal terdapat perbedaan sebesar $10 \%-15 \%$ hal ini disebabkan oleh nilai resistor pengganti yang memiliki toleransi sebesar $\pm 5 \%$ dan sensor ZMPT101B yang memiliki error sebesar $11 \%$ untuk tegangan $15 \mathrm{~V}-12 \mathrm{~V}$. Dari penjelasan di atas dapat dipahami bahwa percobaan simulasi relay jarak ini tingkat akurasinya masih belum bisa mendekati relay jarak yang dipakai di GI Kalibakal, karena error yang dihasilkan masih terlalu besar.

\section{KESIMPULAN}

Dari hasil pembuatan dan penelitian alat Simulasi Relay Jarak Sebagai Proteksi Saluran Transmisi maka diperoleh kesimpulan sebagai berikut:

1. Pada sistem Simulasi Relay Jarak Sebagai Proteksi Saluran Transmisi Dengan Penentuan Lokasi Titik Gangguan Menggunakan Arduino ini telah berhasil dibuat dan diujikan pada 5 jenis gangguan yaitu gangguan R-N, S-N, T-N, R-S, dan S-T.

2. Hasil pengujian modul simulasi gangguan setelah dibandingkan dengan data real gangguan relay jarak pada GI Kalibakal miliki prosentase error antara 10\% -15\%. Hal ini bisa disebabkan oleh nilai resitor yang memiliki toleransi $\pm 5 \%$ dan error pada sensor ZMPT101B sebesar $11 \%$.

3. Pada beberapa kondisi ketika perekaman pada data base terdapat data yang sama masuk ke Microsoft Access mengalami duplikat data yang dimana ada 2 data yang sama dalam 1 waktu. Hal ini bisa disebabkan oleh jeda perekaman data yang terlalu cepat sehingga terjadi duplikat data.

\section{DAFTAR PUSTAKA}

[1] Widiarsana, I. M., Mataram, I. M., \& Sudarmojo, Y. P. (2018). Identifikasi Jenis Gangguan pada Jaringan Transmisi Menggunakan Metode Jaring Syaraf Tiruan. Majalah Ilmiah Teknologi Elektro, 17(1), 1.

[2] Syofian, A. (2017). Analisa Perhitungan Titik Gangguan pada Saluran Transmisi Menggunakan Metode Takagi Aplikasi PT. CHEVRON PACIFIC Indonesia Andi Syofian, M. T Jurusan Teknik Elektro Fakultas Teknik Industri, Institut Teknologi Padang (ITP) E_mail: andisyofianmt@g. 6(2), 204-208.

[3] Zimmerman, K., \& Costello, D. (2005). Impedance-based fault location experience. 2005 58th Annual Conference for Protective Relay Engineers, 2005, 211-226.

[4] Shrivastava, K., \& Vishwakarma, D. N. (2007). Microcontroller-based numerical quadrilateral relay for the transmission line protection. Electric Power Components and Systems, 35(12), 1301-1315.

[5] Aryanto, T., Sutarno, \& Sunardiyo, S. (2013). Frekuensi Gangguan Terhadap Kinerja Sistem Proteksi di Gardu Induk 150 KV Jepara. Jurnal Teknik Elektro, Vol. 5(2), 10.

[6] Bandri, S. (2016). Studi Settingan Distance Relay Pada Saluran Transmisi 150 kV Di GI Payakumbuh Menggunakan Software Matlab. Vol: 5, N(2252), 108-112.

[7] Das, Swagata et al (2013). Impedance-based Fault Location in Transmission Networks: Theory and Application, 2169 - 3536 (c) 2013 IEEE, 2 - 3.

[8] Fitriandi, A., Komalasari, E., \& Gusmedi, H. (2016). Rancang Bangun Alat Monitoring Arus dan Tegangan Berbasis Mikrokontroler dengan SMS Gateway. Rekayasa Dan Teknologi Elektro, 10(2), 8798.

[9] KEPDIR, P. P. (Persero) (2014) 'Buku Pedoman Pemeliharaan Trafo Tenaga'.

[10] Koley, E., Kumar, R., \& Ghosh, S. (2016). Low cost microcontroller based fault detector, classifier, zone identifier and locator for transmission lines using wavelet transform and artificial neural network: A hardware co-simulation approach. International Journal of Electrical Power and Energy Systems, 81, $346-360$. 
[11] Korjenić, K., Kurtić, E., \& Akšamović, A. (2018). Implementation of algorithm for detection of single phase fault with electric arc on dsPIC30F4103 microcontroller. 17.

[12] Tandel, M., Joshi, U., \& Golhani, A. (2017). Scripting Engine for SCADA HMI 1. 492-496.

[13] Wahyuningsih, R. A., Supriyatna, \& Muljono, A. B. (2015). Analisis Koordinasi Proteksi Relay Jarak ( Distance Relay ) Pada Saluran Udara Tegangan Tinggi ( Sutt ) 150 Kv Sistem Kelistrikan Lombok Distance Relay Protection Coordination Analysis of High Voltage. 1-11.

[14] Waikar, D. L., Elangovan, S., Liew, A. C., \& Sng, S. H. (1995). Real-time assessment of a symmetrical component and microcontrollerbased distance relay. Electric Power Systems Research, 32(2), 107-112. 
